\section{Iron chelating agents for iron overload diseases}

\author{
Guido Crisponi, ${ }^{1}$ Valeria Marina Nurchi, \\ Maria Antonietta Zoroddu² \\ 'Department of Chemical and Geological \\ Sciences, University of Cagliari, \\ Monserrato (CA); ${ }^{2}$ Department of \\ Chemistry and Pharmacy, University \\ of Sassari, Italy
}

\begin{abstract}
Although iron is an essential element for life, an excessive amount may become extremely toxic both for its ability to generate reactive oxygen species, and for the lack in humans of regulatory mechanisms for iron excretion. Chelation therapy has been introduced in clinical practice in the seventies of last century to defend thalassemic patients from the effects of iron overload and, in spite of all its limitations, it has dramatically changed both life expectancy and quality of life of patients. It has to be considered that the drugs in clinical use present some disadvantages too, this makes urgent new more suitable chelating agents. The requirements of an iron chelator have been better and better defined over the years and in this paper they will be discussed in detail. As a final point the most interesting ligands studied in the last years will be presented.
\end{abstract}

\section{Introduction}

Although iron is an essential element for life, an excessive amount may become extremely toxic for the human body both for its ability to generate reactive oxygen species (ROS), and for the lack in humans of regulatory mechanisms for iron excretion. ${ }^{1}$ Human protection from iron induced damages involves the degradation of $\mathrm{H}_{2} \mathrm{O}_{2}$ to water and oxygen by the enzymes glutathione peroxidase and catalase, the regulation of total unbound iron by iron binding proteins to prevent hydroxyl radical formation, and the interruption of the radical chain reactions by radical scavengers. In situations of iron imbalance however iron, no more bound to proteins, is involved in redox reactions leading to ROS generation; whenever these situations exceed the antioxidant defense of the organism, oxidative tissue damage occurs, ${ }^{2}$ as in the case of hemochromatosis and $\beta$-thalassemia (transfusion induced iron overload). Chelation therapy was introduced in clinical practice in the seventies of last century to defend thalassemic patients from the toxic effects of iron overload. Among the numerous tasks of iron chelating agents, deeply discussed in several reviews, ${ }^{3-8}$ the main ones consist in creating a favorable equilibrium between transfusional iron assumed by patients and that excreted in a chelated form, in protecting against the circulating non transferrin bound iron which via Fenton reaction easily leads to ROS production, and in scavenging iron stores from organs and tissues in which exert their toxic action. The quantification of iron stores in tissues can be accomplished by iron determination in liver biopsies, ${ }^{9,10}$ or by magnetic resonance imaging ${ }^{11}$ or by superconducting quantum interference device magnetic susceptibility. ${ }^{12,13}$

The first used iron chelator has been desferoxamine (DFO): this chelating agent, in spite of all its limitations, has dramatically changed both life expectancy and quality of life of patients preventing the complications of iron overload; ${ }^{14,15}$ as stated by Bernhardt ${ }^{7}$ the $\beta$-thalassemic patients now in their 50's ... are living proof of the value of this drug. The principal drawbacks of desferoxamine are the lack of oral activity, its high cost and the low compliance. The joined research efforts of clinicians, biochemists and chemists to improve the knowledge of iron metabolism and of the requisites of iron chelators has led to the introduction in clinical use of two new oral chelators deferiprone (DFP) and deferasirox (DFX) (Figure 1) at the beginning of this century. These drugs are extremely useful in the treatment of iron overload, but they too present some disadvantages, which make urgent the need of new chelating agents more suitable from a clinical point of view. ${ }^{2,6}$ In the Novartis advices for DFX ${ }^{16}$ a warning is reported against renal toxicity of this drug: Exjade can cause acute renal failure, fatal in some patients and requiring dialysis in others. Postmarketing experience showed that most fatalities occurred in patients with multiple comorbidities and who were in advanced stages of their hematological disorders. According Hider ${ }^{17}$ DFX, although able to readily enter the cells because of its lipophilicity, forms at physiological $\mathrm{pH}$ a negatively 3 - charged iron complex that cannot easily efflux from cells. This feature of iron complex could explicate the nephrotoxic effects of DFX. The formation of stable polymeric complexes with $\mathrm{Zn}^{2+}$ can further contribute to toxic action of DFX. The notably high pZn of DFX (9.44), larger than those of DFO (6.01) and DFP (6.24), has to be remarked.

In the last seven years a number of papers were published on the comparison of cost effectiveness of chelation therapy in transfusion dependent thalassemia patients. ${ }^{18-22}$ The common results for the US ${ }^{18}$ and $\mathrm{UK}^{19,21}$ healthcare system perspectives on the cost effectiveness of oral DFX vs infusional DFO suggest
Correspondence: Guido Crisponi, Department of Chemical and Geological Sciences, University of Cagliari, Cittadella Universitaria, I-09042 Monserrato (CA), Italy.

Tel. +39.070 .6754476 - Fax: +39.070 .6754478 .

E-mail: crisponi@unica.it

Key words: iron chelator, $\beta$-thalassemia, $\mathrm{pFe}$, hydroxypyridinone, deferoxamine.

Acknowledgements and funding: this work was supported by Regione Autonoma Sardegna FSE Sardegna 2007-2013 L.R.7/2007, project Integrated approach in the design of chelators for the treatment of metal overload diseases, CRP27564 .

Contributions: the authors contributed equally.

Conflict of interests: the authors declare no potential conflict of interests.

Received for publication: 30 October 2013.

Revision received: 22 June 2014.

Accepted for publication: 27 July 2014.

This work is licensed under a Creative Commons Attribution 3.0 License (by-nc 3.0).

CC Copyright G. Crisponi et al., 2014

Licensee PAGEPress, Italy

Thalassemia Reports 2014; 4:2046

doi:10.4081/thal.2014.2046

that DFX is cost effective compared to standard chelation with DF0, while a different conclusion is reached by Luangasanatip et al. ${ }^{20}$ in Thailand. The two studies that perform a cost analysis of DFP ${ }^{20,22}$ both suggest that DFP is the most cost-effective cure for the treatment of iron overload in $\beta$-thalassemia patients.

The design of new improved iron chelators must take into account specific chemical properties.

The requirements of an iron chelator, better and better defined over the years, can be outlined as:

- Favorable toxicity profile of chelating agent and of its complexes;

- Stability of its complexes, higher than that with endogenous ligands;

- Selectivity toward iron;

- Suitable redox potential of complexes;

- It should not be transformed into inactive metabolites in the body;

- Good intestinal absorption and good bioavailability to the target cells;

Fast kinetic exchange of iron between chelator and endogenous ligands;

Factors favoring excretion of the formed complexes;

- It must not disturb the metabolic metal homeostasis in the body fluids.

Further issues govern the suitability of an iron chelator, as its cost and the patient com- 
pliance with its mode of administration. The principal chemical requirements will be discussed in detail in the following sections, and as a final point we will present some of the most interesting ligands studied in the last years.

\section{Stability of the complexes}

The necessary property of a chelating agent is the stability of its complexes that must be entirely formed before their excretion. Depending on the number of the coordinating groups which can bind a given metal ion at the same time a chelator can be classified as bidentate, tridentate and so on. The number of the formed complexes and their stoichiometries are determined by the denticity of the ligand. Hexadentate chelators are ideal for Fe $\mathrm{Fi}^{\mathrm{III}}$, since they form only 1:1 complexes, while lower denticity ligands form complexes of variable stoichiometry, in amounts depending on total ligand concentration and on meta/ligand ratio. Lower stoichiometry iron complexes are sometimes dangerous, for example they do not avoid the reduction of $\mathrm{Fe}^{\mathrm{III}}$ to $\mathrm{Fe}^{\mathrm{II}}$ leading to ROS production via Fenton reaction. In contrast, bidentate and tridentate ligands may be favored with respect to hexadentate chelators, since they can be orally active for their lower molecular weight. Oral activity is a highly requested property of a drug: it cuts therapy costs and increases the tolerability by the patients.

A metal-ligand system is completely determined from the thermodynamic point of view when its speciation model is known on the basis of the stoichiometry and of the stability constants of the formed species. Each complex-formation reaction in a system containing a metal ion $\mathrm{M}$, a ligand $\mathrm{L}$ and the proton $\mathrm{H}$ is described by the general equation:

$$
p \mathrm{M}+q \mathrm{~L}+r \mathrm{H} \leftrightarrows \mathrm{M}_{\mathrm{p}} \mathrm{L}_{q} \mathrm{H}_{\mathrm{r}}
$$

and the corresponding formation constant, at given temperature and ionic strength, is given by:

$$
\beta=\frac{\left[M_{p} L_{q} H_{r}\right]}{[M]^{p}[L]^{q}[H]^{r}}
$$

where charges and coordinated solvent molecules are omitted for simplicity. The terms in square brackets are the molar concentrations of the complex and of the free components; the coefficient $r$ assumes negative values when the number of protons released from the ligand is higher than the number of protons released in absence of metal ion, or when hydroxylated species are formed.

Actually the real effective binding capacity of a ligand cannot be directly inferred from the stability constant, but it depends on a variety of factors, the principal ones being the competition between metal and proton for the same basic sites on the ligand, and the stoichiometry of the formed complexes. This real efficacy is generally evaluated by parameter $\mathrm{pM}$, defined as $-\log [\mathrm{M}]$ at $[\mathrm{M}]_{\mathrm{Tot}}=1 \times 10^{-6} \mathrm{M}$ and $[\mathrm{L}]_{\text {Tot }}=1 \times 10^{-5} \mathrm{M}$ at pH 7.4, where $[\mathrm{M}]$ is the concentration of free metal ion and $[\mathrm{M}]_{\text {Tot }}$ and $[\mathrm{L}]_{\text {Tot }}$ are the total concentrations of metal and ligand, respectively. Iron chelators are normal- ly compared on the basis of pFe values calculated from data at $25^{\circ} \mathrm{C}$ and $0.1 \mathrm{M}$ ionic strength. A pFe value $>20$ is required for efficiently scavenge iron from biological matrices. Some conventional ways of calculating this value have to be remembered, which, if not properly used, can produce misleading results: in the model used for the calculation of pFe the protonation constants of the ligand and the formation constants of all formed complexes have to be taken into account, but the hydroxide formation constants must not be considered, otherwise all the ligands whose pFe is lower than that due to the hydroxide formation, should result in a similar pFe.

\section{Effect of substituent}

Interesting good linear correlations are found when the protonation constants and the iron complex formation constants of given classes of ligands are considered. In particular, examining the protonation and the stability constants of pyridinones, reported in Table 1,23-26 good linear correlations are found between the first protonation constant and the formation constants $\log K_{11}, \log K_{12}$ and $\log K_{13}$ relative to FeL, $\mathrm{FeL}_{2}$ and $\mathrm{FeL}_{3}$ complexes respectively, as well as with the second protonation constant $\log \mathrm{K}_{2}$ (Figure $2 \mathrm{~A}$ ).

These correlations are a clear indication that the same properties determine proton and iron binding. If one assumes that the $\log \mathrm{K}_{1}$ values of pyridinone ligands can be modulated by proper substituents, the $\log \mathrm{K}_{2}$ and $\log K_{11}$, $\log K_{12}, \log K_{13}$ values, also determined by the effect of substituents, can be estimated by the

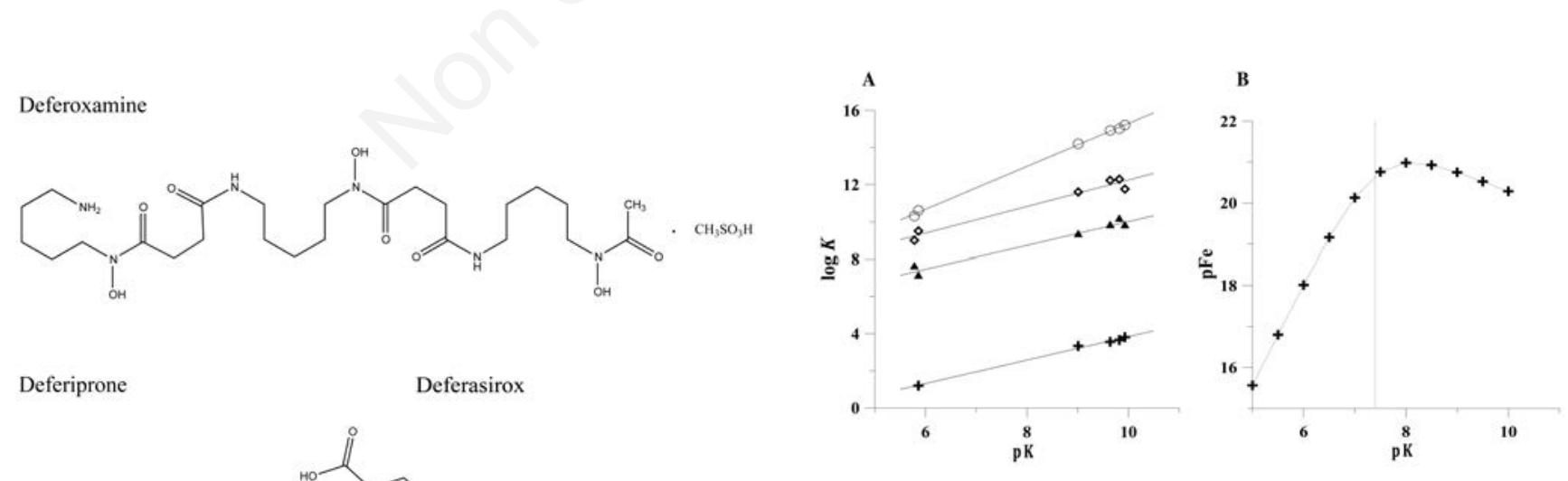

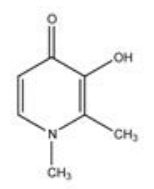

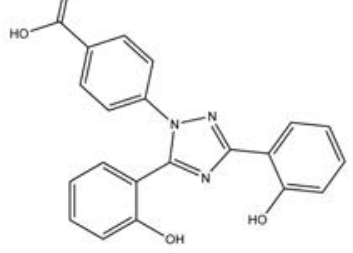

Figure 1. Formulas of the three iron chelating agents currently in use.
Figure 2. A) The formation constants $\log K_{11}(\bigcirc), \log K_{12}(\diamond)$ and $\log K_{13}(\Delta)$ (relative to the complexes $\mathrm{FeL}, \mathrm{FeL}_{2}$ and $\mathrm{FeL}_{3}$, formed between iron ${ }^{\mathrm{III}}$ and the pyridinones in Table 1) and the second protonation constant $\log \mathrm{K}_{2}(+)$ are reported $v s$ the first protonation constant $\log \mathrm{K}_{1}$. B) $\mathrm{pFe}$ calculated from the set of constants obtained as a function of $\log K_{1}$. (Reprinted from Coordination Chemistry Reviews, Vol 252, Crisponi G., Remelli M., Iron chelating agents for the treatment of iron overload, Pages No. 1225-1240, Copyright (2008), with permission from Elsevier). 
parameters of the above straight lines. These values allow to evaluate the pFe values of substituted pyridinones as a function of $\log K_{1}$, reported in Figure 2B.

The main feature of Figure $2 \mathrm{~B}$ is the break point that can be observed at $\log K_{1}$ 7.4. This implies that, when starting from a pyridinone ligand characterized by a $\mathrm{pK} 1<7.4$, a substituent that increases the $\mathrm{pK} 1$ value till to 7.4 , and all the related constants, has the effect of increasing the pFe. On the contrary, when starting from a ligand with $\mathrm{pK} 1>7.4$, an increase of the pFe can be obtained introducing substituents whose inductive and resonance effects lead to a decrease of $\mathrm{pK}_{1}$ till to 7.4. The effect of $\mathrm{pK}_{1}$ in determining the $\mathrm{pFe}$ value has been also remarked by Piyamangkol et al. ${ }^{27}$ These authors described a number of 2 and 6-amido-3-hydroxypyridin-4-ones, all characterized by lower $\mathrm{p} K_{\mathrm{a}}$ values than that of deferiprone, because of the inductive effect of the amido group. Moreover, the $\mathrm{p} K_{\mathrm{a}}$ values of 1 nonsubstituted pyridinones containing the 3 hydroxy group are dramatically lower than those of the corresponding 1-alkyl analogues. This is due to a strong hydrogen bond between the 2-amido function and the 3-oxygen anion, stabilizing the anion. The pFe values of this group of molecules result higher than that of deferiprone as a consequence of the decreased proton competition.

\section{Selectivity toward iron}

Metal selectivity is of paramount importance in the chemical design of iron chelators for clinical application. Iron chelating agents can be designed for either the Fe $\mathrm{F}^{\mathrm{II}}$ or Fe $\mathrm{Fe}^{\mathrm{III}}$ oxidation states. High-spin $\mathrm{Fe}^{\mathrm{III}}$, a spherically symmetrical tripositive cation of radius $0.65 \mathrm{~A}^{\circ}$, classified as a hard metal ion on the basis of its high charge density, forms the most stable complexes with hard ligands, such as those containing charged oxygen atoms. In contrast, $\mathrm{Fe}^{\mathrm{II}}$ has a relatively low charge density and prefers ligands characterized by soft donor atoms. Ligands for $\mathrm{Fe}^{\mathrm{II}}$ maintain a considerable affinity for other bivalent metal ions, such as $\mathrm{Cu}^{\mathrm{II}}$ and $\mathrm{Zn}^{\mathrm{II}}$, of biological relevance, so an $\mathrm{Fe}^{\mathrm{II}}$ selective ligand is not realistic. On the contrary, Fe ${ }^{\mathrm{III}}$-selective ligands, based on oxyanions form more stable complexes with trivalent cations than with divalent cations. Since trivalent cations, as $\mathrm{Al}^{\mathrm{III}}$ and $\mathrm{Ga}^{\mathrm{III}}$, are not essential for living organisms Fe ${ }^{\mathrm{III}}$ is selectively complexed by iron chelators in a biological environment.

The interaction of chelating agents with metal ions besides the toxic target one can be determinant for the drug bioavailability and for possible side effects. For this reason the rigorous determination of the thermodynamic parameters of the complexes with the main endogenous bivalent metal ions, such as $\mathrm{Cu}$, $\mathrm{Zn}, \mathrm{Ca}, \mathrm{Mg}$, has to be performed at standardized conditions representative of the biological fluid.

\section{Suitable redox potential of complexes}

As pointed out in a previous section, the toxic action of a redox-active metal ion as $\mathrm{Fe}^{\mathrm{III}}$ depends on the formation of reactive oxygen species that cause remarkable injuries to tissues and organs. ${ }^{28,29}$ To prevent ROS formation in the organism, the quantity of unbound iron is limited by iron binding proteins. ${ }^{2}$ Nevertheless, iron can be mobilized from these proteins in iron imbalance conditions, and in such situations takes part in redox reactions and generates ROS. Whenever these events go beyond the antioxidant protection, oxidative damages occur. In such cases iron redox potential can be controlled by making use of proper chelating agents, which avoid ROS production. Siderophores molecules, with high selectivity for $\mathrm{Fe}^{\mathrm{III}}$, prevent redox cycling of iron at biological conditions. On the contrary, when nitrogen based ligands are used, characterized by lower redox potentials, coordinated iron is no more protected and can be enzymatically reduced. In the review of Bernhardt ${ }^{7}$ the cyclic voltammetry results for the iron com-

\section{Good intestinal absorption and good bioavailability}

Table 1. Protonation constants $\left(\log K_{1}, \log K_{2}\right)$ and iron complex formation constants $\left(\log K_{11}, \log K_{12}\right.$ and $\left.\log K_{13}\right)$ for some pyridinones.

\begin{tabular}{lccccccc} 
Ligand & $\log K_{1}$ & $\log K_{2}$ & $\log K_{11}$ & $\log K_{12}$ & $\log K_{13}$ & $R e f$. \\
1-Hydroxy-2- pyridinone & 5.86 & 1.2 & 10.61 & 9.5 & 7.1 & 23 \\
1-Hydroxy-2- pyridinone & 5.78 & -- & 10.3 & 9.0 & 7.6 & 24 \\
\hline 3-Hydroxy-4- pyridinone & 9.01 & 3.34 & 14.2 & 11.6 & 9.3 & 24 \\
1,2-Dimethyl-3-hydroxy-4- pyridinone & 9.82 & 3.66 & 15.01 & 12.3 & 10.1 & 25 \\
\hline 1,2-Diethyl-3-hydroxy-4- pyridinone & 9.93 & 3.81 & 15.21 & 11.76 & 9.78 & 26 \\
\hline
\end{tabular}

This Table is reprinted from Coordination Chemistry Reviews, Vol 252, Crisponi G., Remelli M., Iron chelating agents for the treatment of iron overload, Pages No. 1225-1240, Copyright (2008), with permission from Elsevier.

According $\operatorname{Hider}^{37}$ the three main factors governing diffusion through biological membranes are molecular size, lipophilicity and net charge. In particular the molecular weight of drugs to be absorbed in the human gut should not exceed 500 Da. Lipophilicity is generally estimated by the water-octanol partition coefficient (P). These factors have been proposed by Lipinski et al. ${ }^{38}$ to evaluate membrane permeability by a four parameter analysis. According these authors a good absorption is likely when: 
i) molecular weight $<500 \mathrm{Da}$; ii) $\log \mathrm{P}<5$; iii) less than 10 hydrogen bond donors (sum of $\mathrm{OH}$ and $\mathrm{NH}$ groups) are present in the drug; iv) less than 10 hydrogen bond acceptors (sum of $\mathrm{O}$ and $\mathrm{N}$ atoms) are present in the drug.

\section{Fast kinetic exchange of iron between chelator and endogenous ligands}

The behavior of a chelator depends, besides the thermodynamics of complex formation, on kinetic factors, connected to: i) degradation of the chelating agent; ii) complex formation between the chelator and the free metal ion in the plasma; and iii) exchange reaction between the metal bound to endogenous molecules and the chelating agent.

i) Many chelating agents are metabolized in the body to species that loose the chelating properties of the parent molecule. These reactions can be very different, from the glucuronidation of hydroxypyrydinones, to the acetylation of Trien, or the formation of -S-Sbonds between BAL and SH-containing ligands. The correct choice of drug administration becomes of vital importance when this kind of metabolic transformation is rapid, as for example the subcutaneous infusion of deferoxamine.

ii) The circulating toxic iron ions in plasma are generally bound by different endogenous molecules, ranging from large macromolecules as transferrin to low molecular weight ligands as citrate.

iii) The kinetic of the exchange reaction between the ferric ion bound to endogenous molecules and the chelators depends on a variety of factors, among which the structure, the denticity and the size of the chelator. The knowledge of the different kinetic behaviors of the chelators in use has conducted to improved schemes of therapy. In case of iron overload theraphy, in which a more than 30 years experience has been accumulated on deferoxamine action, and at least 20 years for deferiprone, the knowledge of the differences in organ distribution and bioavailability, in target biomolecules and in kinetic and thermodynamic properties, has lead to a combination therapy in which the two chelators exert a synergistic action. $^{39,40}$

\section{Recent research achievements on iron chelating agents}

In this section a surely not exhaustive survey of recent progresses in the study of new iron chelators will be presented. A number of new ligands appeared in literature in the last 10 years, reporting thorough studies of complex formation equilibria and, in some cases, biological evaluations. Particular attention has been paid to 3 -hydroxy-4-pyridinone (3,4-HP) ligand family. The 3,4-HPs are mono-anionic $\mathrm{N}$-heterocyclic molecules that bind $\mathrm{Fe}^{\mathrm{III}}$ with the two oxygen atoms (bidentate $\{0,0\}$ chelators) with high affinity. This family of ligands can be easily extra-functionalized with the aim of improving their properties, above all the bioavailability and the chelating ability. The group of Hider ${ }^{37,41}$ has proposed a variety of bidentate or polydentate 3,4 -HP chelators. In particular they synthesized and studied the chemical properties of different 2- and 6amido-3-hydroxypyridin-4-ones; it is interesting to remark that all these ligands exhibit lower $\mathrm{pK}_{\mathrm{a}}$ values than deferiprone due to the inductive effect of the amido group. These lower pKa's led to a decreased proton competition, so to better chelating properties in comparison with the parent deferiprone. Some ligands of the HP family were also studied for the treatment of toxicity of other hard metal ions: aluminium, by Santos et al..$^{42,43}$ and plutonium by Fukuda. ${ }^{44} \mathrm{~A}$ number of tetradentate 3,4-HP chelators have been studied by the group of Santos; ${ }^{45,46}$ in one case two 3,4-HP chelating moieties were connected by an iminodiacetic acid (IDA) scaffold, with a 1,4-disubstituted arylpiperazine on the nitrogen atom in the linker. The same authors also presented:

- Two hexadentate ligands, based on the KEMP acid scaffold to which three 3-hydroxy-4pyridinone chelating moieties are attached via two differently sized spacers, the trishydroxypyridinone based compounds $\operatorname{KEMPPr}(3,4-\mathrm{HP})_{3}$ and $\mathrm{MPBu}(3,4-\mathrm{HP})_{3}{ }^{47}$ These ligands are very strong chelating agents not only towards iron but also for group III metal ions, with potential clinical applications in metal chelation therapy.

- Two new tris(3-4-HP) hexadentate chelators, $\mathrm{NTA}(\mathrm{BuHP})_{3}$ and NTP(PrHP $)_{3}$, in which the three HP units were connected by nitrilotriacetic acid (NTA) and nitrilotripropionic acid (NTP). Their iron complex formation ability has been studied in solution and their scavenging properties from overloaded animals assayed in vivo. A very strong chelating affinity for Fe must be remarked $\left[\mathrm{pFe}=27.9 \mathrm{NTA}(\mathrm{BuHP})_{3} ; \mathrm{pFe}=29.4\right.$ for $\left.\mathrm{NTP}(\mathrm{PrHP})_{3}\right] .^{48}$

Further families of ligands have been considered as chelators for trivalent metal ions. Biaso et al. ${ }^{49}$ presented two tripodal molecules, 0-TRENSOX, formed by three 8-hydroxy-5-sulfonate-quinoline anchored on tris(2aminoethyl)amine (TREN), as well as analogous triscatechol derivatives TRENCAMS. Impressive pAl values 20.0 and 26.2 for 0 -
TRENSOX and TRENCAMS respectively were reported. Numerous studies on the design, synthesis and complex formation equilibria of variously substituted hydroxypyridinecarboxylic acids have been presented by the group of Di Marco: these ligands are characterized by two coordinating groups $(-\mathrm{OH}$ and $-\mathrm{COOH})$ in various positions $(2,3 ; 3,2 ; 3,4 ; 4,3)$ and differently methylated..$^{50-55}$ A study of our group on bisphosphonate ligands showed their high efficiency as iron chelating agents, reaching pFe values higher than that of deferiprone. ${ }^{56}$ To further improve bisphosphonate chelating properties the conjugation with other strong coordinating groups was proposed. Ding et al. ${ }^{57}$ synthesized catechol-bisphosphonate conjugates and Bailly et al. ${ }^{58}$ mixed bisphosphonatehydroxypyridinonate compounds. With both kinds of ligands the too short linker prevented simultaneous tetradentate coordination..$^{59,60}$ Fox and Taylor ${ }^{61}$ experimented an interesting iron chelator, formed by two kojic acid units linked by a methylene group, for the in vitro mobilization of ferritin-bound iron, and proved its high efficacy. This ligand forms stable iron dinuclear complexes, characterized by the extremely high pFe value $20.5 .^{62}$ On the basis of this interesting chemical result we designed and synthesized a variety of chelators based on two KA units joined by different linkers. ${ }^{63-65}$ In particular those based on a -CH2-NR-CH2linker form $\mathrm{Fe}_{2} \mathrm{~L}_{3}$ complexes in which the three ligands completely satisfy the coordination sphere of two iron ions. The relatively low molecular weight (340-450 Da) characterizes them as possible oral chelators, and the many chances of modulating their binding ability working on proper substituents in the KA units and in the linker offer good perspectives.

Many tetradentate ligands have been investigated to date as possible Fe ${ }^{\text {III }}$ chelators for oral use. In order to completely saturate the six coordination positions on ferric ion, the denticity of these ligands requires formation of polynuclear species, which are invariably found in these systems. In particular, the most common polynuclear complex is the dimer $\mathrm{Fe}_{2} \mathrm{~L}_{3}$, with a charge depending on ligand structure. An especially high affinity for the ferric ion has been found by Santos et al. ${ }^{66}$ concerning the new bis(3-hydroxy-4-pyridinone) derivative of iminodiacetic acid, imino-bis(acetyl(1(3-aminopropyl)-3-hydroxy-2-methyl-4-pyridinone)), IDAPr(3,4-HP) $)_{2}$.

The calculated $\mathrm{pFe}$ value is 25.8 , of the same order of magnitude as that of DFO. However, in the case of IDAPr(3,4-HP $)_{2}$, up to eight complex species form in the explored $\mathrm{pH}$ range (0.4-9), and their relative amount at a defined $\mathrm{pH}$ (e.g. 7.4) depends on the total concentration of both the metal ion and the ligand. 


\section{Conclusions}

In the last thirty years the chemical research has been deeply involved in the synthesis of a large variety of iron chelators according to the structural requisites for their introduction in clinical practice. Despite the significant improvements made in the cure of iron overload with the introduction of deferiprone and deferasirox, and of combined chelation therapy, the clinical results have not been completely satisfactory for the various drawbacks presented by these chelators. The failure to find the ideal iron chelator can be ascribed to inherent difficulties deriving from the biological and clinical restraints.

We think that the large research efforts on these topics have in any way created a large progress in this field, above all with a deeper knowledge of iron metabolism, drug targets, drug absorption mechanisms, relationships between structure and physical-chemical properties, and basic requirements for the different clinical purposes.

We hope that a continuous dialogue among chemists and clinicians, and an ample support to the research in this field, will lead to the common target of prolonging survival and improving the quality of life of iron-loaded patients.

\section{References}

1. Crichton RR. Inorganic biochemistry of iron metabolism, from molecular mechanisms to clinical consequences. Chichester and New York; Wiley; 2001.

2. Crisponi G, Remelli M. Iron chelating agents for the treatment of iron overload. Coord Chem Rev 2008;252:1225-40.

3. Crisponi G, Nurchi VM, Silvagni R, et al. Oral iron chelators for clinical use. Polyhedron 1999;18:3219-26.

4. Faa G, Crisponi G. Iron chelating agents in clinical practice. Coord Chem Rev 1999;184:291-310.

5. Liu ZD, Hider RC. Design of iron chelators with therapeutic applications. Coord Chem Rev 2002;232:151-71.

6. Ma Y, Zhou T, Kong X, et al. Chelating agents for the treatment of systemic iron overload. Curr Med Chem 2012;19:2816-27.

7. Bernhardt PV. Coordination chemistry and biology of chelators for the treatment of iron overload disorders. Dalton Trans 2007;3214-20.

8. Heli H, Mirtorabi S, Karimian K. Advances in iron chelation: an update. Expert Opin Ther Patents 2011;21:819-45.

9. Ambu R, Crisponi G, Sciot R, et al. Uneven hepatic iron and phosphorus distribution in b-thalassemia. J Hepatol 1995;23:544-9.

10. Crisponi G, Ambu R, Cristiani F, et al. Does iron concentration in a liver needle biopsy accurately reflect hepatic iron burden in beta thalassemia?. Clin Chem 2000;46: 1185-8.

11. Argyropoulou MI, Astrakas L. MRI evaluation of tissue iron burden in patients with beta-talassaemia major. Pediatr Radiol 2007;37:1191-200.

12. Nielsen P, Engelhardt R, Duerken M, et al. Using SQUID biomagnetic liver susceptometry in the treatment of thalassemia and other iron loading diseases. Transf Sci 2000;23:257-8.

13. Aessopos A, Farmakis D, Andreopoulos A, et al. Assessment and treatment of cardiac iron overload in thalassemia. Hemoglobin 2009;33:S87-92.

14. Cao A. William Allan Award Address. Am J Hum Genet 1994;54:397-402.

15. Olivieri NF, Nathan DG, MacMillan JH, et al. Survival in medically treated patients with homozygous beta-thalassemia. N Engl J Med 1994;331:574-8.

16. Novartis. Exjade - Highlights of prescribing information. Available from: https:// www.pharma.us.novartis.com/product/pi/p df/exjade.pdf

17. Hider RC. Charge states of deferasirox-ferric iron complexes. Am J Kidney Dis 2010; 55:614-5.

18. Delea TE, Sofrygin 0, Thomas SK, et al. Cost effectiveness of once-daily oral chelation therapy with deferasirox versus infusional deferoxamine in transfusiondependent thalassaemia patients: US healthcare system perspective. Pharmacoeconomics 2007;25:329-42.

19. Karnon J, Tolley K, Oyee J, et al. Cost-utility analysis of deferasirox compared to standard therapy with desferrioxamine for patients requiring iron chelation therapy in the United Kingdom. Curr Med Res Opin 2008;24:1609-21.

20. Luangasanatip N, Chaiyakunapruk N, Upakdee $\mathrm{N}$, et al. Iron-chelating therapies in a transfusion-dependent thalassaemia population in Thailand: a cost-effectiveness study. Clin Drug Investig 2011;31: 493-505.

21. Karnon J, Tolley K, Vieira J, et al. Lifetime cost-utility analyses of deferasirox in betathalassaemia patients with chronic iron overload: a UK perspective. Clin Drug Investig 2012;32:805-15.

22. Bentley A, Gillard S, Spino M, et al. Costutility analysis of deferiprone for the treatment of $\beta$-thalassaemia patients with chronic iron overload: a UK perspective. Pharmacoeconomics 2013;31:807-22.

23. Jin Li Y, Martell AE. Potentiometric and spectrophotometric determination of stabilities of the 1-hydroxy-2-pyridinone com- plexes of trivalent and divalent metal ions. Inorg Chim Acta 1993;214:103-11.

24. Scarrow R, Riley P, Abu-Dari K. Ferric ion sequestering agents. Inorg Chem 1985; 24:954-67.

25. Nurchi VM, Crisponi G, Pivetta T, et al. Potentiometric, spectrophotometric and calorimetric study on iron(III) and copper(II) complexes with 1,2-dimethyl-3hydroxy-4-pyridinone. J Inorg Biochem 2008;102:684-92.

26. Ma R, Reibenspies JJ, Martell AE. Stabilities of 1,2-diethyl-3-hydroxy-4pyridinone chelates of divalent and trivalent metal ions. Inorg Chim Acta 1994; 223:21-9.

27. Piyamongkol S, Ma YM, Kong XL, et al. Amido-3-hydroxypyridin-4-ones as Iron (III) Ligands. Chem Eur J 2010; 16: 6374-81.

28. Chaston TB; Richardson DR. Interactions of the pyridine-2-carboxaldehyde isonicotinoyl hydrazone class of chelators with iron and DNA: Implications for toxicity in the treatment of iron overload disease. $\mathrm{J}$ Biol Inorg Chem 2003;8:427-38.

29. Macakova K, Mladenka P, Filipsky T, et al. Iron reduction potentiates hydroxyl radical formation only in flavonols. Food Chem 2012;135:2584-92.

30. Boukhalfa H, Crumbliss AL. Chemical aspects of siderophores mediated iron transport. BioMetals 2002;15:325-39.

31. Merkofer M, Kissner R, Hider RC, et al. Fenton chemistry and iron chelation under physiologically relevant conditions, Electrochemistry and kinetics. Chem Res Toxicol 2006;19:1263-9.

32. Merkofer M, Kissner R, Hider RC, et al. Redox properties of the iron complexes of orally active iron chelators CP20, CP502, CP509, and ICL670. Helv Chim Acta 2004;87:3021-34.

33. Novartis. Desferal. Available from: http://www.novartis.com.au/products/healt hcare-professionals.shtml

34. Neufeld EJ. Oral chelators deferasirox and deferiprone for transfusional iron overload in thalassemia major: new data, new questions. Blood 2006;107:3436-41.

35. Singh S, Epemolu R0, Dobbin PS, et al. Urinary metabolic profiles in humans and rat of 1,2-dimethyl- and 1,2-diethyl-dibstituted 5-hydroxypyridin-4-ones. Drug Metab Dispos 1992;20:256-61.

36. Waldmeier F, Bruin GJ, Glaenzel U, et al. Pharmacokinetics, metabolism, and disposition of deferasirox in beta-thalassemic patients with transfusion-dependent iron overload who are at pharmacokinetic steady state. Drug Metab Dispos 2010; 38:808-16.

37. Hider RC, Liu ZD. Emerging understanding of the advantage of small molecules such as hydroxypyridinones in the treat- 
ment of iron overload. Curr Med Chem 2003;10:1051-64.

38. Lipinski CA, Lombardo F, Dominy BW, et al. Experimental and computational approaches to estimate solubility and permeability in drug discovery and development settings. Adv Drug Del Rev 1997; 23:3-25.

39. Grady RW, Berdoukas VA, Rachmilewitz EA, et al. Optimizing chelation therapy: combining deferiprone and desferioxamine. Blood 1999;96:604a.

40. Origa R, Bina P, Agus A, et al. Combined therapy with deferiprone and desferrioxamine in thalassemia major. Haematologica 2005;90:1309-14.

41. Liu ZD, Hider RC. Design of clinically useful iron(III)-selective chelators. Med Res Rev 2002;22:26-64.

42. Santos MA. Hydroxypyridinone complexes with aluminium. In vitro/vivo studies and perspectives. Coord Chem Rev 2002;228: 187-203

43. Santos MA, Gil M, Gano L, et al. Bifunctional 3-hydroxy-4-pyridinone derivatives as potential pharmaceuticals: Synthesis, complexation with Fe(III), $\mathrm{Al}(\mathrm{III})$ and $\mathrm{Ga}$ (III) and in vivo evaluation with ${ }^{67} \mathrm{Ga}$. J Biol Inorg Chem 2005;10:56480.

44. Fukuda S, Chelating agents used for plutonium and uranium removal in radiation emergency medicine. Curr Med Chem 2005;12:2765-70.

45. Chaves S, Dron PI, Danalache FA, et al. Combined chelation based on glycosylmono- and bis-hydroxypyridinones for aluminium mobilization: Solution and biodistribution studies. J Inorg Biochem 2009; 103:1521-9.

46. Gama S, Gil M, Gano L, et al. Combined chelation of bi-functional bis-hydroxypiridinone and mono-hydroxypiridinone: synthesis, solution and in vivo evaluation. J Inorg Biochem 2009;103:288-98.

47. Grazina R, Gano L, Sebestik J, et al. New tripodal hydroxypyridinone based chelating agents for $\mathrm{Fe}(\mathrm{III}), \mathrm{Al}(\mathrm{III})$ and $\mathrm{Ga}(\mathrm{III})$ : Synthesis, physico-chemical properties and bioevaluation. J Inorg Biochem 2009; 103:262-73.
48. Chaves S, Marques SM, Matos AMF, et al. New tris(hydroxypyridinones) as iron and aluminium sequestering agents: synthesis, complexation and in vivo studies. Chem Eur J 2010;16:10535-45.

49. Biaso F, Baret P, Pierre JL, et al. Comparative studies on the iron chelators O-TRENSOX and TRENCAMS: selectivity of the complexation towards other biologically relevant metal ions and $\mathrm{Al}(3+)$. J Inorg Biochem 2002;89:123-30.

50. Di Marco VB, Tapparo A, Bertani R, et al. Complex formation between aluminium (III) and two pyridine derivatives: 2hydroxynicotinic and 3-hydroxypicolinic acid. Ann Chim (Rome) 1999;89:535-46.

51. Di Marco VB, Yokel RA, Ferlin MG, et al. Evaluation of 3,4 hydroxypyridinecarboxylic acids as possible bidentate chelating agents for aluminium (III): synthesis and metal-ligand solution chemistry. Eur J Inorg Chem 2002;10:2648-55.

52. Di Marco VB, Dean A, Ferlin MG, et al. Methyl hydroxypyridinecarboxylic acids as possible bidentate chelating agents for aluminium (III): synthesis and metal-ligand solution chemistry. Eur J Inorg Chem 2006;16:1284-93.

53. Bombi GG, Di Marco VB, Marton D, et al. 2hydroxy-3-carboxy-dihydrocinnamic acid: complexation properties towards aluminium(III) and iron(III). Polyhedron 2007; 26:3419-27.

54. Dean A, Ferlin MG, Brun P, et al. Evaluation of 2-methyl-3-hydroxy-4-pyridinecarboxylic acid as a possible chelating agent for iron and aluminium. Dalton Trans 2008;13:1689-97.

55. Dean A, Ferlin MG, Brun P, et al. 1,6Dimethyl-4-hydroxy-3-pyridinecarboxylic acid and 4-hydroxy-2-methyl-3-pyridinecarboxylic acid as new possible chelating agents for iron and aluminium. Dalton Trans 2009;10:1815-24.

56. Gumienna-Kontecka E, Silvagni R, Lipinski R, et al. Bisphosphonate chelating agents: complexation of $\mathrm{Fe}(\mathrm{III})$ and $\mathrm{Al}(\mathrm{III})$ by 1-phenyl-1-hydroxymethylene bisphosphonate and its analogues. Inorg Chim Acta 2002; 339:111-8.
57. Ding H, Xu G, Wang J, et al. Catechol-bisphosphonate conjugates: New types of chelators for metal intoxication therapy. Heteroatom Chem 2004;15:549-55.

58. Bailly T, Burgada R, Prange T, et al. Synthesis of tetradentate mixed bisphosphonates - new hydroxypyridinonate ligands for metal chelation therapy. Tetrahedron Lett 2003;44:189-92.

59. Crisponi G, Nurchi VM, Pivetta T. Potentiometric and spectrophotometric equilibrium study on Fe(III) and new catechol-bisphosphonate conjugates. J Inorg Biochem 2008;102:209-15.

60. Crisponi G, Nurchi VM, Pivetta T, et al. Towards a new attenuating compound: A potentiometric, spectrophotometric and NMR equilibrium study on $\mathrm{Fe}(\mathrm{III}), \mathrm{Al}(\mathrm{III})$ and a new tetradentate mixed bisphosphonate-hydroxypyridinonate ligand. J Inorg Biochem 2008;102:1486-94.

61. Fox RC, Taylor PD. Bis(5-hydroxy-2hydroxymethyl-pyran-4-one-6-yl)methane: a novel ligand for the intracellular mobilisation of ferritin-bound iron. Bioorg Med Chem Lett 1998;8:443-6.

62. Nurchi VM, Crisponi G, Lachowicz JI, et al. Iron(III) and aluminium(III) complexes with hydroxypyrone ligands aimed to design kojic acid derivatives with new perspectives. J Inorg Biochem 2010;104:560-9.

63. Nurchi VM, Lachowicz JI, Crisponi G, et al. Kojic acid derivatives as powerful chelators for iron(III) and aluminium(III). Dalton Trans 2011;40:5984-98.

64. Toso L, Crisponi G, Nurchi V, et al. A family of hydroxypyrone ligands designed and synthesized as iron chelators. J Inorg Biochem 2013;127:220-31.

65. Toso L, Crisponi G, Nurchi VM, et al. Searching for new aluminium chelating agents: a family of hydroxypyrone ligands. J Inorg Biochem 2014;130:112-21.

66. Santos MA, Gama S, Gano L, et al. A new bis(3-hydroxy-4-pyridinone)-IDA derivative as a potential therapeutic chelating agent. Synthesis, metal-complexation and biological assays. Dalton Trans 2004;21: 3772-81. 